\title{
Favipiravir use for SARS CoV-2 infection
}

\author{
Alberto Boretti ${ }^{1}$ (1) \\ Received: 14 September 2020 / Revised: 8 October 2020 / Accepted: 14 October 2020 / Published online: 27 October 2020 \\ (c) Maj Institute of Pharmacology Polish Academy of Sciences 2020
}

\begin{abstract}
Introduction The pandemic of SARS CoV-2 has required urgent medical treatments for numerous patients. As no specific antiviral agents were available, different off-the-shelf alternatives have been explored.

Objective Here, we review the rationale behind the use of Favipiravir, and report of the specific studies supporting this treatment being conducted.

Methods Here we analyze the relevant literature to conclude about the present opportunities offered by this therapeutic agent. Results This antiviral drug approved influenza in Japan since 2014, has a demonstrated in vitro activity against SARS CoV-2 and is being investigated in several trials for SARS CoV-2. Signals of benefit were shown in a small trial for SARS CoV-2. However, in another small study, there was no advantage.

Conclusions Further studies, statistically more significant, are urgently needed to understand the best opportunities offered by this treatment.
\end{abstract}

Keywords SARS CoV-2 $\cdot$ Favipiravir $\cdot$ Human trials $\cdot$ Animal studies $\cdot$ Laboratory experiments

\section{Introduction}

Initial estimations of the SARS CoV-2 mortality rate were extremely large, at about $1 \%$ of the infected in the simulations of [1]. Then [2], that first investigated the number of those with SARS CoV-2 antibodies in the supposed to be unaffected population, demonstrated the existence of a significant amount of people asymptomatic or mild. Thus, the revised SARS CoV-2 mortality rate is about $0.12-0.20 \%$. The daily peak fatality rates for the United Kingdom, predicted by [1] were 210 . The measured peak fatality rate for the United Kingdom (7-days rolling averages) has been less than 14. Countries that enforced less severe restrictions such as Sweden or the Netherlands did better at below 10 than countries such as the United Kingdom that had 14 or Belgium that had 30 [3]. For Saudi Arabia, the fatality rate (percentage of deaths in closed cases) is $0.83 \%$ ( 549 over 66,339 , as per the data updated June 3) [4]. The above $0.83 \%$ is not the infection fatality rate, which is the number of deaths from the SARS

Alberto Boretti

deanshipofresearch@pmu.edu.sa

1 Prince Mohammad Bin Fahd University, PO Box 1664, Al Khobar 31952, Kingdom of Saudi Arabia
CoV-2 disease divided by the total number of cases of SARS CoV-2, but only the fatality rate in medium-tosevere cases requiring medical attention. According to the World Health Organization (WHO), their data to early March were already suggesting that $80 \%$ of the infections were mild or asymptomatic, $15 \%$ were severe infection, requiring oxygen and $5 \%$ were critical infections, requiring ventilation [5]. By taking $20 \%$ of the $0.83 \%$ fatality rate in closed cases between the medium-to-severe SARS CoV-2 cases, the fatality rate of Saudi Arabia is, therefore, $0.166 \%$ [4], within the range indicated by [2]. As a reference, the death rate for influenza and pneumonia for Saudi Arabia [6] is 49.64 per 100,000 or $0.050 \%$. Thus, the fatality rate of SARS CoV-2 is more than the flu. In addition, the fatality is mostly limited to the vulnerable [7-9]. In a healthy population, a strong immune system resulting from exercise, good nutrition, and regular supplements of vitamins and minerals is a guarantee of safety against SARS CoV-2. The Charles de Gaulle aircraft carrier case is a proof. Of almost 2000 people supposed to be healthy and with a strong immune system likely all uniformly challenged by the virus, only 1081 were infected, and of the 1081 , only 24 ended up in the hospital, with only 1 of them in need of intensive care [9]. After less than 2 weeks, there were only two Marines still 
in the hospital, and one of them still in need of intensive care [9]. After 3 weeks, only the one previously in intensive care was still hospitalized but out of the intensive care [9]. Thus, the fatality rate in this sample of the total Charles de Gaulle aircraft carrier population was thus zero.

It is within this context, of therapies mostly needed in patients with an immune system compromised for age or comorbidities, where contraindications may exist for the use of the more toxic drugs, that SARS CoV-2 therapies must be applied. Within this context, it is necessary to carefully consider the safety-to-efficacy profile of the drugs used for SARS CoV-2 therapy.

In people with a weak immune system, for ages or comorbidities, drug toxicity may constitute a serious threat to the survival of the patients, producing in some cases more damage than benefit. The last controversy about chloroquine and hydroxychloroquine is focused on the safety-to-efficacy profile [10-12]. Thus, it is extremely relevant to evaluate therapies with minimal side effects and contraindications.

\section{Favipiravir use for SARS CoV-2 infection}

An emerging drug now becoming popular in Japan and Russia is Favipiravir.

Figure 1a is the molecule of Favipiravir (from https:// molview.org/?cid=492405).

Favipiravir (Avigan) is a known antiviral for influenza [13]. It is indicated for novel influenza strains that cause more severe disease rather than seasonal influenza [13]. Favipiravir triphosphate is a purine nucleoside analog. Favipiravir is a member of pyrazines and a primary carboxamide.

Figure $1 \mathrm{~b}$ is the molecule of Oseltamivir, as Favipiravir and Oseltamivir are often combined. Oseltamivir is a cyclohexenecarboxylate ester. It is an antiviral prodrug being hydrolyzed to the active free carboxylic acid in the liver. Oseltamivir is used to slow the spread of influenza. It has a role as a prodrug, an EC 3.2.1.18 (exo-alpha-sialidase) inhibitor, an antiviral drug, an environmental contaminant, and a xenobiotic.

The mechanism of action is likely the selective inhibition of viral RNA-dependent RNA polymerase [14, 15]. In vitro
Fig. 1 a Favipiravir molecule from molview.org/?cid $=492405$. The formula is $\mathrm{C}_{5} \mathrm{H}_{4} \mathrm{FN}_{3} \mathrm{O}_{2}$. The molecular weight is $157.1 \mu \mathrm{g}$, hydrogen bond donors 2, hydrogen bond acceptors 4 . Percent composition is C $12.0107 \mu \mathrm{g} \times 5$ $38.226 \%$; H $1.00794 \mu \mathrm{g} \times 4$, 2.5663\%; F $18.998404 \mu \mathrm{g} \times 1$, $12.093 \%$; N $14.0067 \mu \mathrm{g} \times 3$, $26.747 \%$; and $\mathrm{O} 15.9994 \mu \mathrm{g} \times 2$, $20.368 \%$. Systematic name is 5-fluoro-2-oxo- $1 \mathrm{H}$-pyrazine3-carboxamide. b Oseltamivir molecule from molview. org/?cid=65028. The formula is $\mathrm{C}_{16} \mathrm{H}_{28} \mathrm{~N}_{2} \mathrm{O}_{4}$. The molecular weight is $312.4 \mu \mathrm{g}$, hydrogen bond donors 2 , hydrogen bond acceptors 5. Percent composition is $\mathrm{C} 12.0107 \mu \mathrm{g} \times 16$, $61.514 \%, \mathrm{H} 1.00794 \mu \mathrm{g} \times 28$, $9.0339 \%, \mathrm{~N} 14.0067 \mu \mathrm{g} \times 2$, $8.9670 \%$, and O $15.9994 \mu \mathrm{g} \times 4$, $20.485 \%$
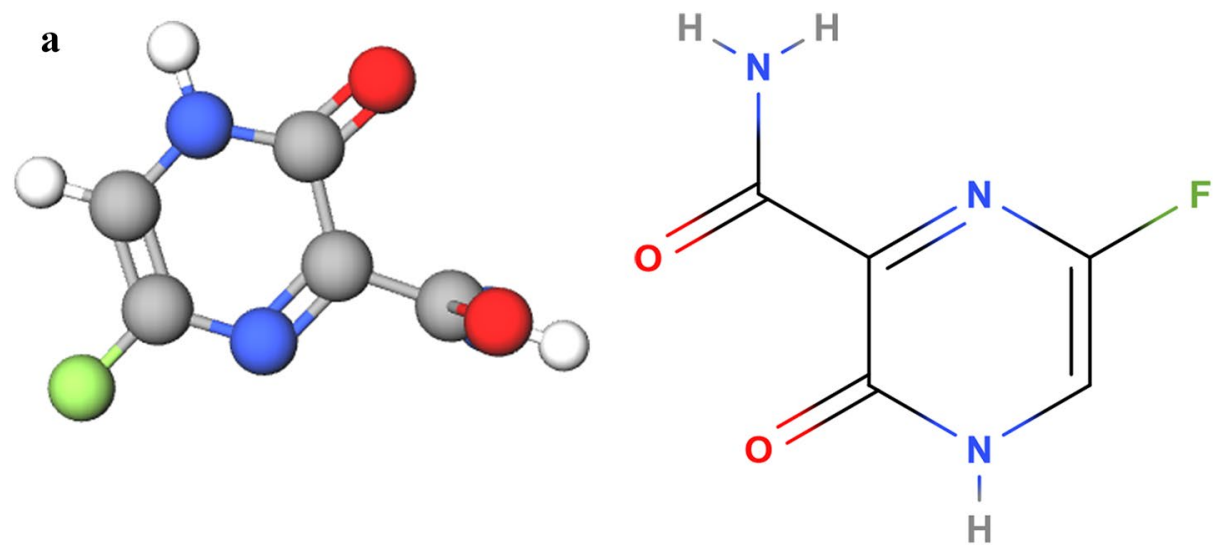

b

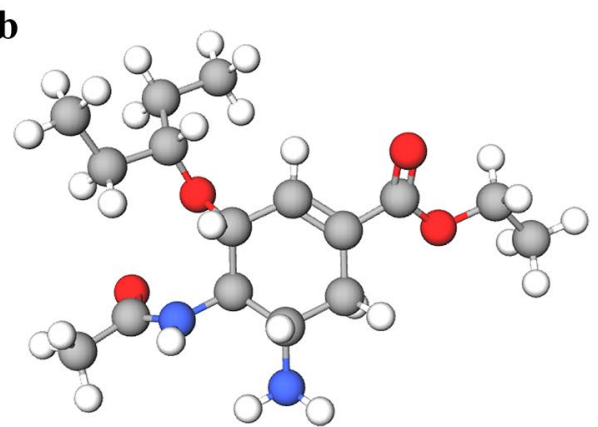


studies on influenza A H1N1 viruses suggesting induced lethal RNA transversion mutations through the production of nonviable viral phenotype $[16,17]$ suggest that Favipiravir works as a chain terminator at the site of incorporation of the viral RNA thus reducing the viral load. Shiraki and Daikoku [17] advocate the use of Favipiravir against novel influenza strains. Favipiravir does not inhibit RNA or DNA synthesis in mammalian cells and it is not toxic to mammalian cells [18]. However, Favipiravir also seems not effective in primary human airway cells [19]. This may cast doubts about the efficacy in the use for SARS CoV-2 infection.

Favipiravir works against a broad range of influenza viruses [20]. These include $\mathrm{A}(\mathrm{H} 1 \mathrm{~N} 1)$ pdm09, $\mathrm{A}(\mathrm{H} 5 \mathrm{~N} 1)$ and $A(H 7 N 9)$ avian virus [20]. Favipiravir also inhibits influenza strains resistant to current antiviral drugs, and produce a synergistic effect in combination with Oseltamivir [20]. A small trial of 168 patients severely ill from influenza were treated with Favipiravir plus Oseltamivir (40) and Oseltamivir alone (128) [21]. A combination of Favipiravir and Oseltamivir accelerates clinical recovery [21].

For the specific use against SARS CoV-2, [22] evaluated the in vitro efficacy of different drugs, from Remdesivir to Chloroquine, also including Favipiravir. With Favipiravir, half-maximal effective concentration $\mathrm{EC}_{50}=61.88 \mu \mathrm{M}$, $\mathrm{CC}_{50}>400 \mu \mathrm{M}, \mathrm{SI}>6.46$ were required to reduce the viral infection. Wang, Cao, Zhang, Yang, Liu, and Xu et al. [22] recommended further in vivo studies as efficacy against the Ebola virus challenge in mice was large despite an $\mathrm{EC}_{50}$ value in Vero E6 cells as high as $67 \mu \mathrm{M}$.

$\mathrm{Li}$ and De Clercq [23] include Favipiravir together with Remdesivir, Galidesivir, and Ribavirin in between the existing antiviral agents' RNA-dependent RNA polymerase inhibitors to repurpose to treat SARS CoV-2 infection. Dong et al. [24] also include Favipiravir, together with Chloroquine, Arbidol, and Remdesivir, all under clinical studies in China to test their efficacy and safety for SARS CoV-2 infection. Costanzo et al. [25] declare Favipiravir as one of the most promising drugs for SARS CoV-2, however, mentioning only the small study [26] discussed hereafter as supporting evidence. These are, however, experts' opinions not supported by proper trials.

Favipiravir safety evidence in the treatment of other pathologies is reviewed in Ref. [27]. Study follow-up was between 5 and 21 days. The proportions of grade 1-4 adverse events (AE) on Favipiravir was $28.2 \%$ vs $28.4 \%$ in the comparison arms with Oseltamivir, Umifenovir, and Lopinavir/ Ritonavir. The proportion of discontinuations due to $\mathrm{AE}$ on Favipiravir was $1.1 \%$ vs $1.2 \%$ in the comparison arms. Serious AEs were $0.4 \%$ in both arms. While Favipiravir demonstrates a favorable safety profile, safety concerns remain for hyperuricemia, teratogenicity, and QTc prolongation [28].

Regarding SARS CoV-2 application, according to [29], for analogies with the treatment with the same drug of the
Ebola virus, while the drug $\mathrm{EC}_{50}$ against $\mathrm{SARS} \mathrm{CoV}-2$ is $9.4 \mu \mathrm{g} / \mathrm{m}$ they suggest a higher value of $\mathrm{EC}_{50}$, in the range of $40-80 \mu \mathrm{g} / \mathrm{mL}$, about same of the Ebola dosage. Cardiac and hepatic monitoring during treatment is suggested, the same as monitoring of Favipiravir concentration [29]. In addition to the in vitro study [22] indicating that Favipiravir (T-705) inhibited SARS CoV-2 replication in Vero E6 cells with $\mathrm{EC}_{50}$ values of $61.88 \mu \mathrm{M}(9.4 \mu \mathrm{g} / \mathrm{mL})$, the independent study [30] indicated $\mathrm{EC}_{50}$ values $>100 \mu \mathrm{M}(15.7 \mu \mathrm{g} / \mathrm{mL})$. As Favipiravir is a prodrug requiring metabolic activation in the host cells to form its triphosphate form, this may contribute to the differences between the two studies [28].

Up to date, there is not enough information from specific trials to infer any conclusion on the use of Favipiravir for SARS CoV-2 infection. An open-label non-randomized trial of only 80 patients performed in China [26] was reported in the literature. This work was published in one engineering rather than a medical journal. This small study found a reduced viral clearance time, improved CT scan, and fewer side effects in comparison to Lopinavir/Ritonavir [26].

Recently, in a small trial of 240 SARS CoV-2 patients, 120 were treated with Favipiravir and 120 with Arbidol [31]. Among patients with SARS CoV-2, in comparison, Favipiravir did not significantly improve the clinical recovery rate on Day 7 but improved the latency to relief for pyrexia and cough. Favipiravir had mild and manageable adverse effects.

There are a few ongoing trials. clinicaltrials.gov [32] reports as per June 6, 2020, 1416 SARS CoV-2 Studies from the World Health Organization Database. A search for Favipiravir returns 20 trials. The total number of Favipiravir trials for SARS CoV-2 and other applications is 73 (Table 1) (from [33]). Those with results are a small percentage of the total.

\section{Discussion and conclusion}

Given the demonstrated in vitro of activity of Favipiravir against SARS CoV-2 and signals of benefit in early clinical experience for SARS CoV-2, but also the existence of contraindications that limit the window of cases where the safety-to-efficacy profile is promising, further studies are urgently needed.

The literature works that reviewed specific Favipiravir use for SARS CoV-2 are mostly comments, letters to the editors, or replies, and not research works reporting gold standard trials passed through a proper peer review. Results of trials have not yet been reported in the literature, with the only exception of one very small study and not all the parameters needed under control.

General for SARS CoV-2, the trials performed, under particularly challenging circumstances, without proper control of the relevant parameters, and based on a statistically 


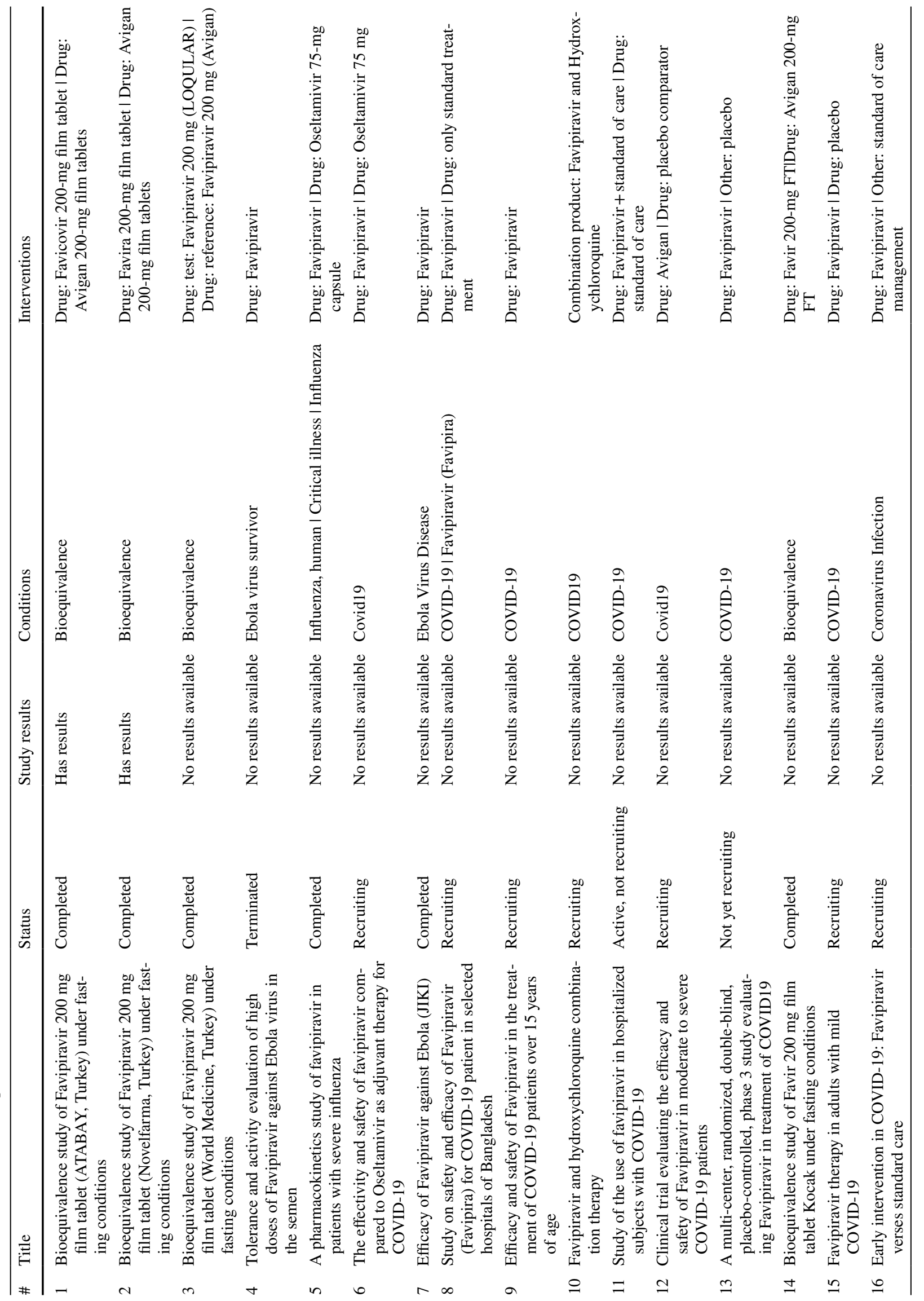




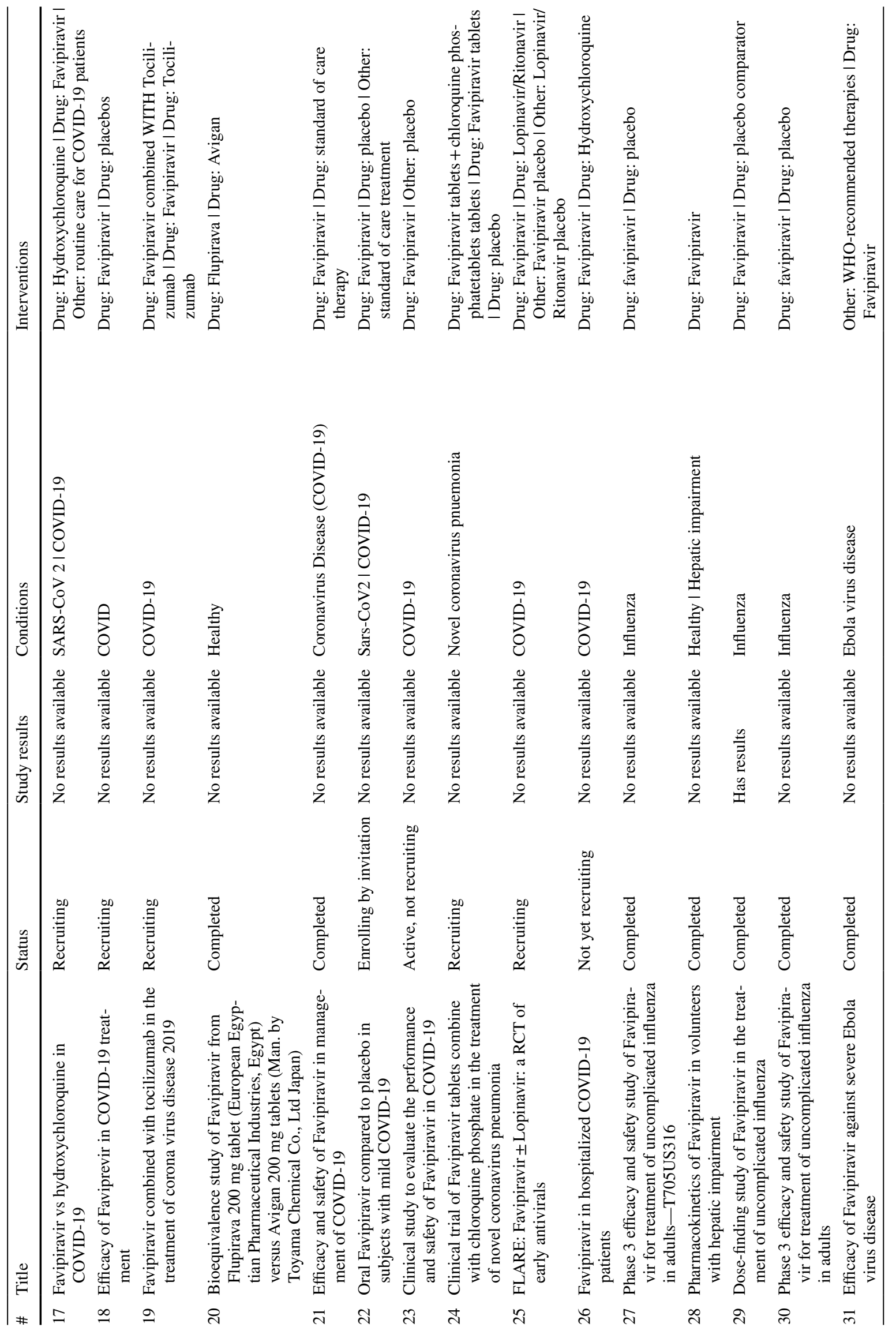




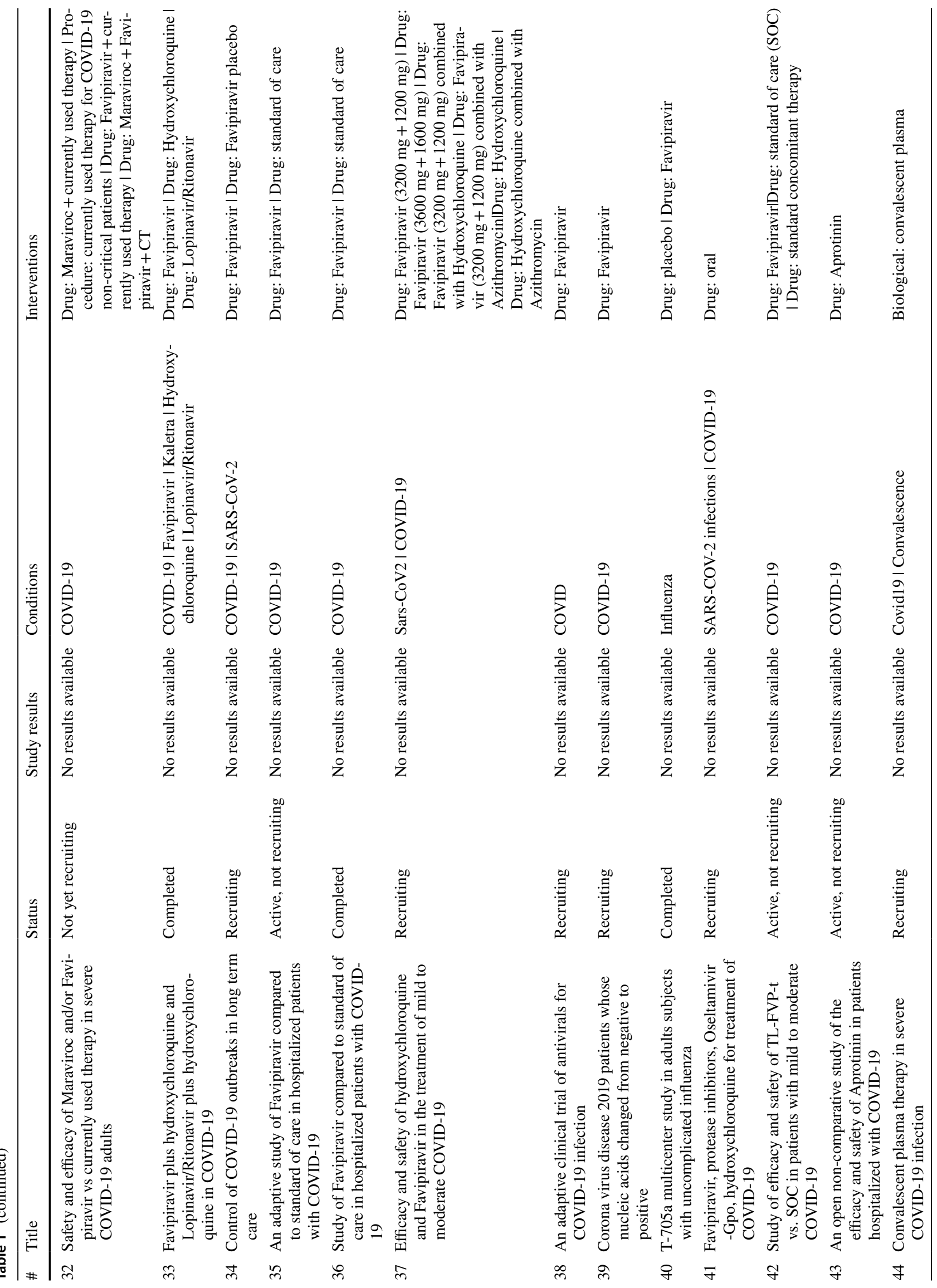




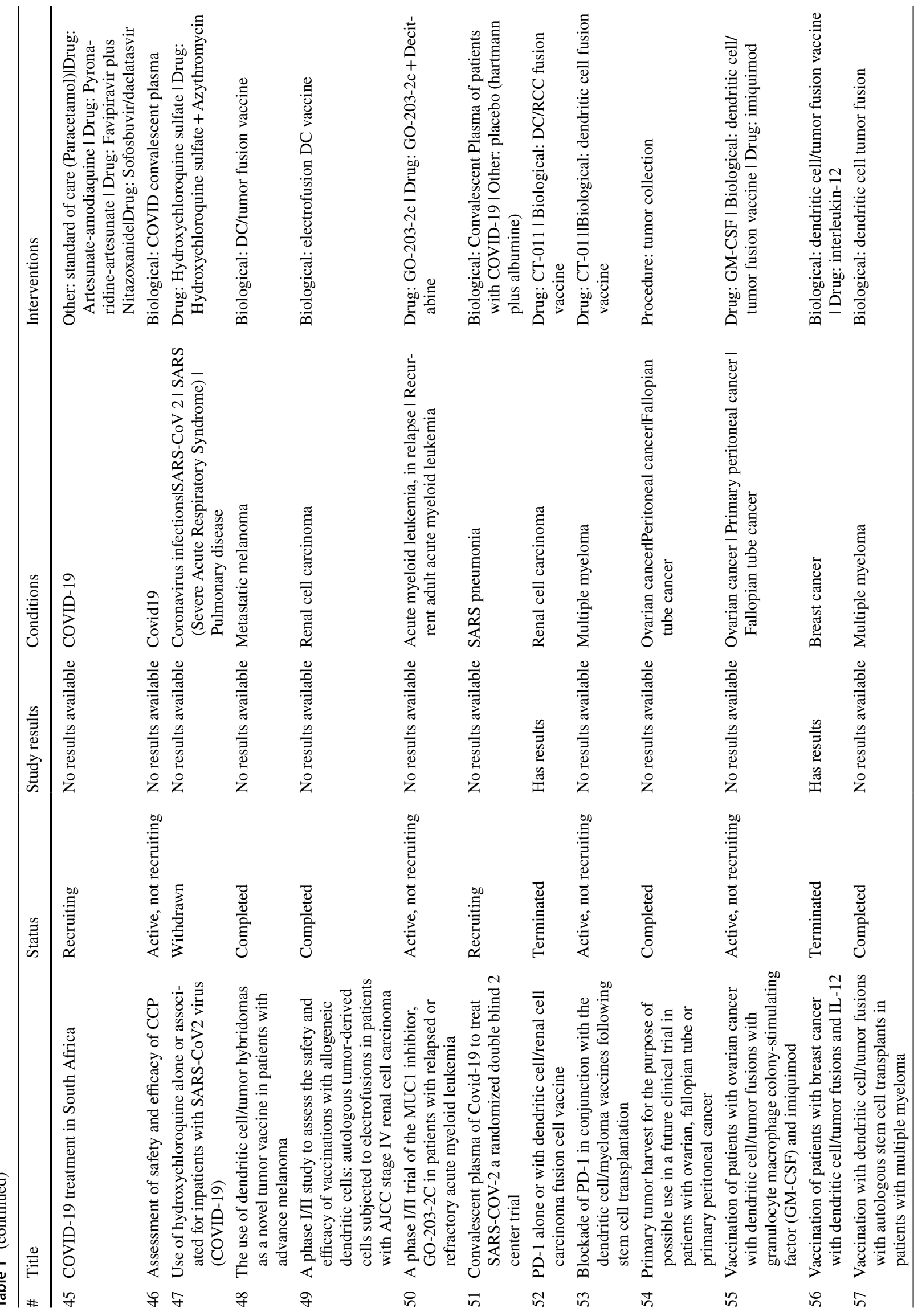




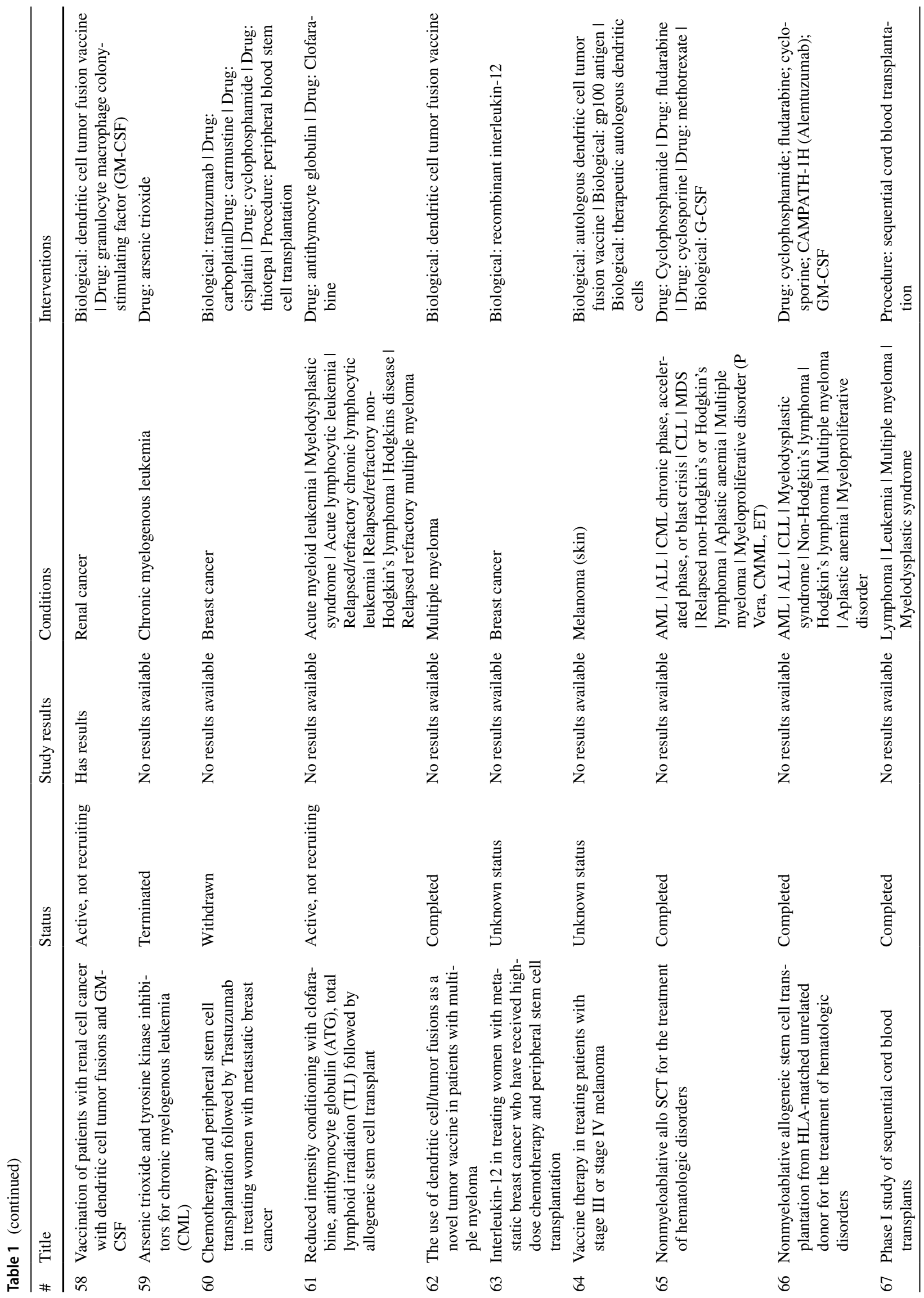




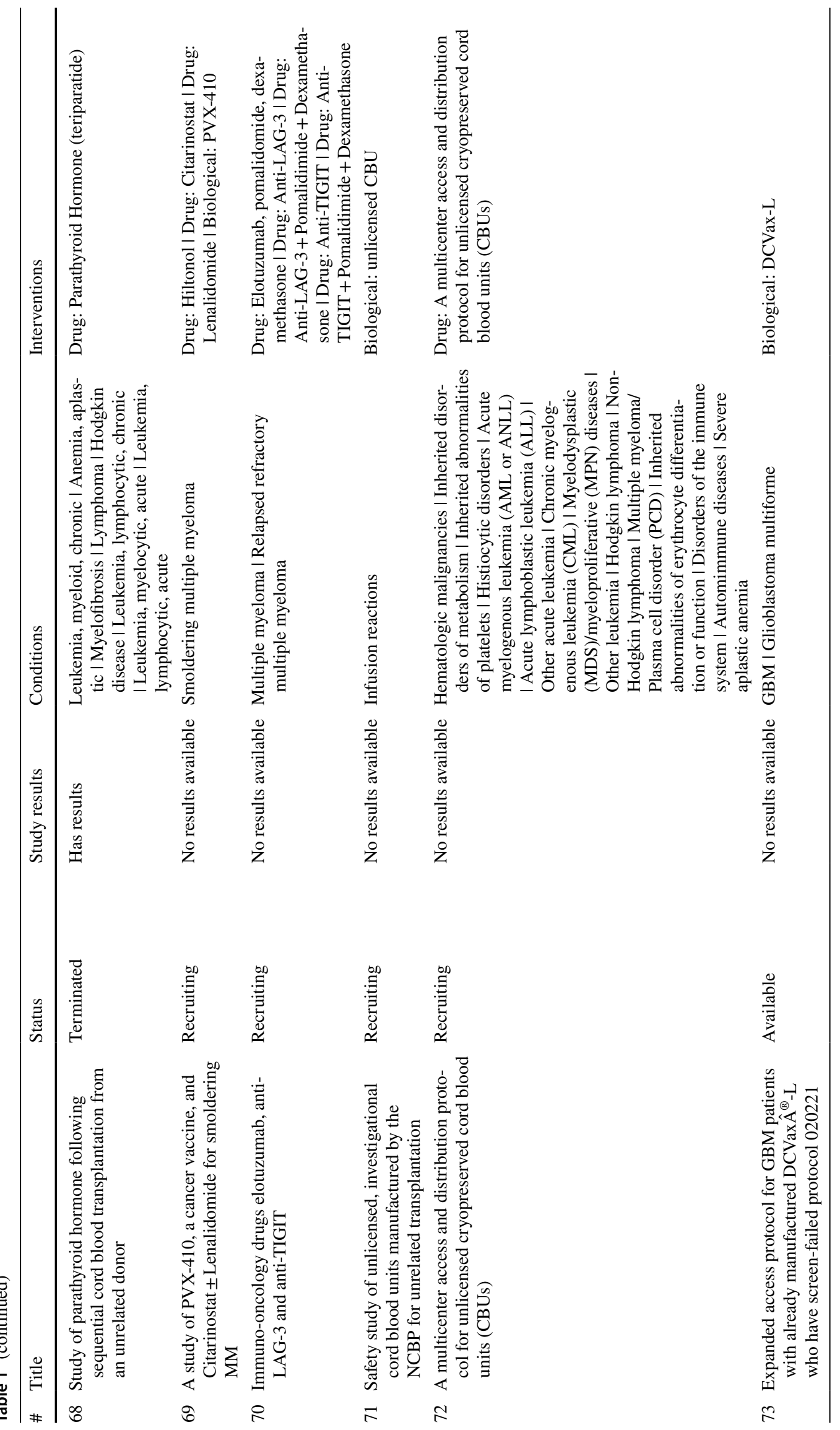


irrelevant population, are not certainly the gold standard in medical research. These experiences have left more doubts than certainties, also because of the conflict of interest affecting the health sector [27], the rush for publishing in SARS CoV-2, and mostly the interference by the Mainstream Media.

Large, randomized, placebo-controlled studies of hospitalized SARS CoV-2 patients conducted without preconceived agenda and properly monitoring all the relevant parameters are urgently needed to understand if Favipiravir, as well as other products, are beneficial, and in which specific cases may be used to treat SARS CoV-2 infection with a positive safety-to-efficacy profile.

Author contributions This is a single author paper.

\section{Compliance with ethical standards}

Conflict of interest The author received no funding and has no conflict of interest to declare.

\section{References}

1. Ferguson N, Laydon D, Nedjati Gilani G, Imai N, Ainslie K, Baguelin M, Bhatia S, Boonyasiri A, Cucunuba Perez ZU, Cuomo-Dannenburg G, Dighe A. Report 9: impact of non-pharmaceutical interventions (NPIs) to reduce COVID19 mortality and healthcare demand. https://doi.org/10.25561/77482.

2. Bendavid E, Mulaney B, Sood N, Shah S, Ling E, Bromley-Dulfano R, Lai C, Weissberg Z, Saavedra R, Tedrow J, Tversky D. COVID-19 antibody seroprevalence in Santa Clara County, California. MedRxiv. 2020. https://doi.org/10.1101/2020.04.14.20062 463v1.full.pdf.

3. Boretti A. After less than 2 months, the simulations that drove the world to strict lockdown appear to be wrong, the same of the policies they generated. Health Serv Res Manag Epidemiol. 2020a;16(7):2333392820932324. https://doi.org/10.1177/23333 92820932324

4. Boretti A. COVID-19 fatality rate for Saudi Arabia, updated 3 June 2020. J Glob Antimicrob Resist. 2020b;1(22):845-6. https ://doi.org/10.1016/j.jgar.2020.07.014.

5. https://www.who.int/docs/default-source/coronaviruse/situa tion-reports/20200306-sitrep-46-covid-19.pdf?sfvrsn=96b04 adf_4\#: :text=For\%20COVID\%2D19\%2C,infections\%2C\%20 requiring\%20ventilation. Accessed 3 June 2020.

6. https://www.worldlifeexpectancy.com/cause-of-death/influenzapneumonia/by-country/. Accessed 3 June 2020.

7. Boretti A. Sustainable post Covid19 lockdown strategy through evidence-based policy: analysis of Covid19 fatalities across Europe. Integr J Med Sci. 2020c;7:172. https://doi.org/10.15342 /ijms.7.172.

8. Boretti A. Analysis of the Charles De Gaulle aircraft carrier Covid19 epidemic: infectivity and fatality in the young, healthy, active population: lesson from the Charles de Gaulle aircraft carrier Covid19 experience. Integr J Med Sci. 2020d;7:174. https:// doi.org/10.15342/ijms.7.174.

9. Boretti A. Some doubt the Covid19 containment measures on the generally healthy population made any difference for Italy:
Covid19 fatalities much larger in Europe, United States and Canada than elsewhere. Integr J Med Sci. 2020e;7:179. https:// doi.org/10.15342/ijms.7.179.

10. Mehra MR, Desai SS, Ruschitzka F, Patel AN. Hydroxychloroquine or chloroquine with or without a macrolide for treatment of COVID-19: a multinational registry analysis. Lancet. 2020. https://doi.org/10.1016/S0140-6736(20)31180-6.

11. Mehra MR, Ruschitzka F, Patel AN. Hydroxychloroquine or chloroquine with or without a macrolide for treatment of COVID-19: a multinational registry analysis. Lancet. 2020. https://doi.org/10.1016/S0140-6736(20)31324-6.

12. Piller C, Servick K. Two elite medical journals retract coronavirus papers over data integrity questions. Science. 2020 (10.1126). https://www.sciencemag.org/news/2020/06/two-elite -medical-journals-retract-coronavirus-papers-over-data-integ rity-questions. Accessed 5 June 2020

13. Du YX, Chen XP. Favipiravir: pharmacokinetics and concerns about clinical trials for 2019-nCoV infection. Clin Pharmacol Ther. 2020a. https://doi.org/10.1002/cpt.1844.

14. Jin Z, Smith LK, Rajwanshi VK, Kim B, Deval J. The ambiguous base-pairing and high substrate efficiency of T-705 (favipiravir) ribofuranosyl 5'-triphosphate towards influenza A virus polymerase. PLoS ONE. 2013;8(7):e68347.

15. Coomes EA, Haghbayan H. Favipiravir, an antiviral for COVID19? J Antimicrob Chemother. 2020. https://doi.org/10.1093/jac/ dkaa171.

16. Baranovich T, Wong SS, Armstrong J, Marjuki H, Webby RJ, Webster RG, Govorkova EA. T-705 (favipiravir) induces lethal mutagenesis in influenza A H1N1 viruses in vitro. J Virol. 2013;87(7):3741-51.

17. Shiraki K, Daikoku T. Favipiravir, an anti-influenza drug against life-threatening RNA virus infections. Pharmacol Ther. 2020;22:107512.

18. Furuta Y, Takahashi K, Shiraki K, Sakamoto K, Smee DF, Barnard DL, Gowen BB, Julander JG, Morrey JD. T-705 (favipiravir) and related compounds: novel broad-spectrum inhibitors of RNA viral infections. Antiviral Res. 2009;82(3):95-102.

19. Yoon JJ, Toots M, Lee S, Lee ME, Ludeke B, Luczo JM, Ganti K, Cox RM, Sticher ZM, Edpuganti V, Mitchell DG. Orally efficacious broad-spectrum ribonucleoside analog inhibitor of influenza and respiratory syncytial viruses. Antimicrob Agents Chemother. 2018;62(8):e00766-18.

20. Furuta Y, Gowen BB, Takahashi K, Shiraki K, Smee DF, Barnard DL. Favipiravir (T-705), a novel viral RNA polymerase inhibitor. Antivir Res. 2013;100(2):446-54.

21. Wang Y, Fan G, Salam A, Horby P, Hayden FG, Chen C, Pan J, Zheng J, Lu B, Guo L, Wang C. Comparative effectiveness of combined favipiravir and oseltamivir therapy versus oseltamivir monotherapy in critically ill patients with influenza virus infection. J Infect Dis. 2020;221(10):1688-98.

22. Wang M, Cao R, Zhang L, Yang X, Liu J, Xu M, Shi Z, Hu Z, Zhong W, Xiao G. Remdesivir and chloroquine effectively inhibit the recently emerged novel coronavirus (2019-nCoV) in vitro. Cell Res. 2020;30(3):269-71.

23. Li G, De Clercq E. Therapeutic options for the 2019 novel coronavirus (2019-nCoV). Nat Rev Drug Discov. 2020. https://doi. org/10.1038/d41573-020-00016-0.

24. Dong L, Hu S, Gao J. Discovering drugs to treat coronavirus disease 2019 (COVID-19). Drug Discov Ther. 2020;14(1):58-60.

25. Costanzo M, De Giglio MA, Roviello GN. SARS-CoV-2: recent reports on antiviral therapies based on lopinavir/ritonavir, darunavir/umifenovir, hydroxychloroquine, remdesivir, favipiravir and other drugs for the treatment of the new coronavirus. Curr Med Chem. 2020. https://doi.org/10.2174/092986732766620 0416131117. 
26. Cai Q, Yang M, Liu D, Chen J, Shu D, Xia J, Liao X, Gu Y, Cai Q, Yang Y, Shen C. Experimental treatment with favipiravir for COVID-19: an open-label control study. Engineering. 2020. https ://doi.org/10.1016/j.eng.2020.03.007.

27. Pilkington V, Pepperrell T, Hill A. A review of the safety of favipiravir - a potential treatment in the COVID-19 pandemic? J Virus Erad. 2020;6(2):45.

28. Du YX, Chen XP. Response to "Dose rationale for favipiravir use in patients infected with SARS-CoV-2." Clin Pharmacol Ther. 2020b. https://doi.org/10.1002/cpt.1878.

29. Eloy P, Solas C, Touret F, Mentré F, Malvy D, de Lamballerie $\mathrm{X}$, Guedj J. Dose rationale for favipiravir use in patients infected with SARS-CoV-2. Clin Pharmacol Ther. 2020. https://doi. org/10.1002/cpt.1877.

30. Choy KT, Wong AY, Kaewpreedee P, Sia SF, Chen D, Hui KP, Chu DK, Chan MC, Cheung PP, Huang X, Peiris M. Remdesivir, lopinavir, emetine, and homoharringtonine inhibit SARS-CoV-2 replication in vitro. Antivir Res. 2020;3:104786.

31. Chen C, Huang J, Cheng Z, Wu J, Chen S, Zhang Y, Chen B, $\mathrm{Lu}$ M, Luo Y, Zhang J, Yin P. Favipiravir versus arbidol for COVID-19: a randomized clinical trial. MedRxiv. 2020. https:// doi.org/10.1101/2020.03.17.2003743.

32. https://clinicaltrials.gov/ct2/who_table. Accessed 3 Oct 2020.

33. https://clinicaltrials.gov/ct2/results? cond $=\&$ term $=$ Favipiravi $r \& c n t r y=\&$ state $=\&$ city $=\&$ dist $=$. Accessed 3 Oct 2020 .

Publisher's Note Springer Nature remains neutral with regard to jurisdictional claims in published maps and institutional affiliations. 